\title{
SCHOOL-AGE CHILDREN AWARENESS OF THE CAUSES OF OBESITY AND ITS HEALTH RELATED OUTCOMES
}

\author{
Chaychenko T.V., Gonchar M.O., Chumachenko T.O., Klymenko V.A., \\ Samsonenko T., Kharkova M.O
}

Kharkiv National Medical University, Ukraine

\begin{abstract}
Childhood obesity is a serious medical condition affecting children and adolescents that can be prevented by life style modification. Therefore, school-age children awareness of the causes of obesity and its health related outcomes is very importan. Subjects Methods This work is a part of the complex project "Assessment of the current nutritional status, nutritionrelated health problems in school-age children in Ukraine". The total number of participants is 392 school-age children who were grouped by the age: primary school $(75$ children aged 6-9), secondary school (202 children aged 10-14) and high school (115 children aged 1518). Original questionnaire was elaborated for the survey, consisting of both multiple choice questions and "open questions" that encouraged children to give their own idea with the purpose of understanding a real awareness of the problem. Answers to the open questions about the causes and effects of obesity were assessed. Results One third of respondents regardless of age (primary school, $-29.31 \%$, secondary school $-29.21 \%$, high school $33.04 \%, \mathrm{p}>0.05$ ) understood that obesity can cause serious health problems and the most detrimental changes can occur in the cardiovascular system. It was established that selfcontrolled situations were named as the main causatives of the obesity by more than half of surveyed children $(53.33 \%$ of primary school, $53.46 \%$ of secondary school children and $41.74 \%$ high school children, $\mathrm{p}>0.05$ ). We established that less than $10 \%$ of children were not aware of the causes of obesity and possible outcomes. Meantime, 30\% of respondents were not prone to give any answer. Conclusions: Regardless of age school-children are aware of health-related problems caused by obesity. Special education programs are necessary for all school-age children with the purpose of developing the responsibility for the health in their adult life.
\end{abstract}

Key words: Obesity, causes of overweight, school-age children, social education program.

Introduction

Number of overweight people is about 2.1 billion around the world. It exceeds the amount of starving people by 2.5 times [1]. There is a tendency to an increase in obesity rate not only in adult, but in pediatric population as well. The incidence of pediatric obesity increased dramatically within one generation [2]. Thus, 42 billion of children under 5 years are overweight or obese [3].

The main feature of this epidemic is that it can be prevented by life style modification [4], that may well lead to the cardiovascular risk

Corresponding Author:

Tetyana Chaychenko, MD, PhD, Professor of Department of Pediatrics 1 and Neonatology of Kharkiv National Medical University, Ukraine. E-mail: tatyana.chaychenko@gmail.com reduction by the improvement of the metabolic parameters [5]. According to the WHO [4] and AHA [6], diet together with exercising are effective tools for the prevention of cardiovascular problems.

$17.77 \%$ children in Ukraine are obese [7]. There is a tendency to the growing number of over non-medication interventions depends on different factors [9] but still is a treatment of choice of pediatric obesity [4].

Thus, study of school-age children awareness of the causes of obesity and its health related outcomes is crucial for the education programs.

2. Purposes, subjects and methods:

2.1 Purpose - to study school-age children awareness of the causes of obesity and its health related outcomes. 


\subsection{Subjects \& Methods}

This work is a part of the research "Assessment of the current nutritional status, nutrition-related health problems in school-age children in Ukraine", conducted at Kharkiv National Medical University for the development and further implementation of social education program for prevention of non-communicable diseases.

A cross-sectoral study was conducted in three different geographic regions of Ukraine. The present data provides survey results of children in Kharkiv region (as a representative of eastern part of country).

Survey assessment of current nutritional status in school-age children of 3 age groups (aged 6-9, 10-14, 15-18), who were randomly selected in urban and rural areas of region, was performed.

The total number of participants was 392 school-age children who were grouped by the age.

The high school group (aged 15-17) consisted of 115 children aged $15.28+1.47$ that included $29(25.22 \%)$ boys and $86(74.78 \%)$ girls.

The secondary school group (aged 10-14) consisted of 202 children aged $12.55+1.40$ that included 95 (47.03\%) boys and $102(52.97 \%)$ girls.

The primary school group (aged 6-9) consisted of 75 children aged $8.20+1.27$ that included 43 (57.33\%) boys and $32(42.67 \%)$ girls.

For the survey the original questionnaire (adapted according to the FAO recommendations) was elaborated for evaluation of broader context (economic, social, environmental factors) that influences nutrition. Questionnaire consists of both multiple choice questions and "open questions" that encouraged children to give their own idea with the purpose of understanding real awareness of the problem. Survey was conducted in the comfortable atmosphere with no pressure from peers, parents or tutors.

Results of the provided data concerning causes and outcomes of obesity were grouped by the self-control (self-controlled, uncontrolled), affected body system and health risk.

Self-controlled causes include such answers as "wrong nutrition", "sedentary lifestyle", "continuous consumption of food", "increased appetite to the tasty food", "habitual eating", "consumption of bakery products", "consumption of sweets", "tasty food", "don't understand that it's a problem", etc.). Uncontrolled causes include such answers as: "stress", "hormonal problems", "diseases", "heredity", "metabolic problems" etc.).

Potential outcomes of obesity were grouped by the body systems.
- Cardiovascular problems: "myocardial infarction", "high blood pressure", "blocked vessels", "tachycardia", "stroke", "heart problems", etc.

• Orthopedic problems: "pain in legs", "difficulty in walking", "joint pain", "posture problems", etc.

- Gastrointestinal problems: "liver disorders", "stomachache", "nausea", "abdominal pain", "digestion problems"

- Endocrine problems: "high blood sugar", "diabetes", "infertility", etc.

• General well-being problems: "weakness", "tiredness", "poor sleeping", "headaches", "depression", etc.)

Potential outcomes of obesity were grouped by the health risk:

- Death or disability associated: "premature death", "myocardial infarction", "stroke", "tumors", etc.

• Chronic diseases: "diabetes", "joint problems", "dyspnea", "liver disorders", "digestion problems", "heart diseases"

• General well-being problems: "weakness", "tiredness", "poor sleeping", "headaches", "depression", etc.)

The study was approved by the institutional Committee in Ethics and Bioethics of Kharkiv National Medical University. Written consent from parents and children was obtained for every participant.

Standard statistics was used for the data analysis.

Conflict of interests. There is no conflict of interests.

\section{Results and discussion}

Children in all groups have chosen selfcontrolled causes of obesity as the most significant (53.33\% of primary school, $53.46 \%$ of secondary school children and $41.74 \%$ high school children).

Number of children who do not know the answer to this question is growing from primary to secondary and declining from secondary to high school age. The number of those who did not respond was statistically higher in high-school group (table 1). This might be suggestive for the substitution of the problem by the non-primary school children whereas they are able to understand the real causes. On the other hand this tendency could be a feature of teenager's behavior.

Recent studies show that more than $60 \%$ of children are aware of childhood obesity and about $40 \%$ know that overeating, decreased outdoor play, spending more time in front of screen (TV, mobile, and laptop) can contribute to it [10]. $75 \%$ of parents in this study to $85 \%$ of obese children's parents are informed about causes of the 
Table 1

Number of children who did not know the answer or did not respond to the question concerning causes of overweight (\% of respondents)

\begin{tabular}{|l|c|c|}
\hline \multicolumn{1}{|c|}{ Age group } & "I do not know" answer & No answer \\
\hline Primary school, $\mathrm{n}=75$ & 2.67 & 34.67 \\
\hline Secondary school, $\mathrm{n}=202$ & 12.38 & 24.75 \\
\hline High school, $\mathrm{n}=115$ & 4.35 & 40.87 \\
\hline Difference & $\mathrm{P}_{13}=0.01$ & $\mathrm{P}_{23}=0.002$ \\
\hline
\end{tabular}

excessive weight, meantime they do not practice this knowledge in parenting their children [11]. It is worth mentioning that the vast majority of them originate from the socioeconomic level. This could be suggestive for the pure family control. Moreover, we have our own data that reflect pure life style control in families with overweight children in forms of episodes of hyper-dominant behavior and complete neglecting of the problem [8]. On the other hand, school-age children are able to keep
Just $5-8 \%$ of respondents are able to see probable link between excessive weight and orthopedic problems (primary school $-8 \%$, secondary school $-7.43 \%$, high school $-5.22 \%$, $\mathrm{p}>0.05$ ).

Number of those who did not know the answer did not differ in groups. Whereas, about quarter of respondents regardless of age were not prone to answer the question about the body system most affected by overweight (table 2).

Table 2

Number of school-age children who did not respond and were unaware of body systems potentially affected by overweight (\% of respondents)

\begin{tabular}{|l|c|c|}
\hline \multicolumn{1}{|c|}{ Age group } & "I do not know" answer & No answer \\
\hline Primary school, $\mathrm{n}=75$ & 4 & 34.68 \\
\hline Secondary school, $\mathrm{n=202}$ & 8.91 & 24.75 \\
\hline High school, $\mathrm{n}=115$ & 4.35 & 25.22 \\
\hline Difference & $>0.05$ & $>0.05$ \\
\hline
\end{tabular}

recommendations on the diet and develop appropriate food priorities [12]. Thus, it is necessary to develop programs for the education of children with no direct involvement of family members due to potential low compliance.

The cornerstone of any educational program is motivation that could be raised by the appreciation of potential outcomes of the problem [13]. Our comparative analysis of the awareness concerning outcomes of overweight demonstrates that children may well understand potential problems, associated with different parts of the body. Meanwhile, the third part of respondents despite of age (primary school, $-29.31 \%$, secondary school $-29.21 \%$, high school $-33.04 \%$, $\mathrm{p}>0.05$ ) consider cardiovascular problems as the most significant. It is an important issue as according to our studies, even overweight and metabolically healthy children are under the risk of cardiovascular problems [14].

About $10 \%$ of population associate obesity with decreased well-being (primary school $-12 \%$, secondary school $-10.89 \%$, high school $-13.91 \%$, $\mathrm{p}>0.05)$. And the same amount - with GIT disorders (primary school $-10.67 \%$, secondary school-13.87\%, high school-12.17\%, $\mathrm{p}>0.05$ ).
Answers of children to the question about overweight outcomes were grouped by the degree of risk for the health and life. We have revealed that children in all age groups understand the link between obesity and acute cardiovascular events, diabetes and cancer (primary school $20 \%$, secondary school $-28.71 \%$, high school $29.57 \%, p>0.05)$. They also understand that excessive body mass can cause general weakness, tiredness, sleep disorders and headache (primary school $-20 \%$, secondary school $-15.35 \%$, high school $-12.7 \%, \mathrm{p}>0.05$ ). This findings suggest appropriate awareness of the problem which is greater than in other middleincome countries $[10,11,16]$. Simultaneously, the number of unreplied subjects varies from 20 to $40 \%$ that is really significant and attracts a particular attention.

\section{Conclusions}

1. School-age children understand that obesity can cause problems with a general well-being, leading to the chronic diseases, disability and even death. Regardless of age children consider that the most detrimental changes can occur in the cardiovascular system (primary school $-29.31 \%$, 
secondary school $-29.21 \%$, high school $-33.04 \%$, $\mathrm{p}>0.05$ ).

2. Self-controlled situations (wrong nutrition, sedentary life style, etc.) were named as the main causatives of obesity by more than half children regardless of age (primary school $-53.33 \%$, secondary school $-53.46 \%$, high school $41.74 \%)$.
3. The number of children who are not aware of obesity causes and potential outcomes is less than $10 \%$. Whereas about $30 \%$ of respondents were not prone to give an answer that is suggestive for the psychological substitution of the problem. Thus, education is necessary for all school-age children with the purpose of developing the responsibility for health in their adult life.

\section{References}

1. Roberto, C. A., Swinburn, B., Hawkes, C. (2015). Patchy progress on obesity prevention: emerging examples, entrenched barriers, and new thinking. Lancet. 385(9985):2400 -2409. doi: 10.1016/ S01406736(14)61744-X.

2. Lobstein, T., Jackson-Leach, R., Moodie, M.L. (2015). Child and adolescent obesity: part of a bigger picture. Lancet. 385(9986): 2510-2520. doi: 10.1016/S0140-6736(14)61746-3

3. World Health Organization Fact sheet № 311. Obesity and overweight (2016). Available from: https://www.who.int/news-room/fact-sheets/detail/obesity-and-overweight

4. WHO Report of the Commission on Ending Childhood Obesity.World Health Organization (2016). 68 P.

5. Ho, M., Garnett, S.P., Baur, L., Burrows, T., Stewart, L., Neve, M., Collins, C. (2012). Effectiveness of life style interventions inchild obesity: systematic reviewwithmeta-analysis. Pediatrics, 130(6), 164771. doi: 10.1542/peds.2012-1176.

6. American College of Cardiology/American Heart Association Task Force on Practice Guidelines OEP. Expert panel report: Guidelines (2013) for the management of overweight and obesity in adults. Obesity (Silver Spring). 2014;22 Suppl 2:S41-S410. doi: 10.1002/ oby.20660.

7. Zelins`ka N. B., Rudenko N. G. (2015) Stan nadannya medy`chnoyi dopomogy` dityam z endokry`nnoyu patologiyeyu v Ukrayini u 2014 roci [The state of medical care for children with endocrine pathology in Ukraine in 2014]. Ukrayins 'ky’j zhurnal dy`tyachoyi endokry`nologiyi, no 2, pp. 5-13.

8. Chaychenko, T., Rybka, O., Georgievska, N., Buginska, N. (2016) Trends of nutrition of eastern Ukrainian children: tendency to overweight, dehydration and impaired social adaptation. Horm Res Pediatr, 86 (S1): 1-556 doi:10.1159/000449142

9. Chaychenko T. (2015) Efekty`vnist`nemedy`kamentozny`x intervencij u ditej z ozhy`rinnyam [Efficacy of non-drug interversion in obese children]Ukrayins `ky`j zhurnal dy` tyachoyi endokry`nologiyi, no 1 (13), pp. 31-35.].

10. Pradeepa, S., Elango, S., Andrews, M., Hanan, R.A., Amritha, S., Ambica, G. (2018). Awareness on childhood obesity among mothers attending pediatrics outpatient department at tertiary care teaching hospital. Int J Med Sci Public Health, 7(9), 760-764.

11. Mabiala Babela, J. R., Nika, E. R., Nkounkou Milandou, K. G., Missambou Mandilou, S. V., Bouangui Bazolana, S. B., Monabeka, H. G., \& Moyen, G. (2016). Knowledge, Attitudes, and Practices of Parents Facing Child and Adolescent Obesity in Brazzaville, Congo. Global pediatric health, 3, 2333794X16675546. doi:10.1177/2333794X16675546

12. Waters, E., de Silva-Sanigorski, A., Hall, B.J., Brown, T., Campbell, K.J., Gao, Y. (2011) Interventions for preventing obesity in children. Cochraine Database Syst. Rev, 12 CD 001871

13. Deforche, B., Haerens, L., Ilse de Bourdeaudhuij (2011) How to make overweight children exercise and follow the recommendations, International Journal of Pediatric Obesity, 6:sup1, 35-41. doi: 10.3109/ 17477166.2011.583660

14. Chaychenko, T. (2016).Risk related cardiovascular changes in metabolically healthy obese adolescents. Polish Annals of Medicine,23, 2, 87-91. doi:10.1016/j.poamed.2016.01.006

15. Aceves-Martins, M., Llaurady, E., Tarro, L., Sola, R., \& Giralt, M. (2016). Obesity-promoting factors in Mexican children and adolescents: challenges and opportunities. Global health action, 9, 29625. doi:10.3402/gha.v9.29625

Received: 02-Feb-2019

Accepted: 14-Mar-2019 